\title{
Assessing the Impact of Water Scarcity on Daily Life of Human Activities in Debre Tabor Town
}

\author{
Tilahun Abie Fetene \\ Department of Geography and Environmental Studies, Kebri Dehar University, Kebri Dehar, Ethiopia
}

Email address:

tilahunabie5@gmail.com

\section{To cite this article:}

Tilahun Abie Fetene. Assessing the Impact of Water Scarcity on Daily Life of Human Activities in Debre Tabor Town. International Journal of Biomedical Materials Research. Vol. 9, No. 1, 2021, pp. 1-9. doi: 10.11648/j.ijbmr.20210901.11

Received: January 11, 2021; Accepted: February 14, 2021; Published: March 10, 2021

\begin{abstract}
Even if much of the earth is covered by mater, the world population was suffered by water scarcity. Its severity also increased from time to time. This problem is affect the present generation to meet their needs and wants and compromises the next generation to sustain economic development and political stability. The study was carried out in Debre tabor town in south Gondar zone of Amhara region, Ethiopia, to assess water scarcity and its impact on daily activity and economic development of the local communities. For this study two Kebele (Kebele 01\&02) were selected. The total household of the two Kebele have 14902 households. From these total populations 99 were selected as respondents by using simple random sampling technique. Primary data were used and collected through interview and questioners and secondary data also collected from published and unpublished material like book, article, senior essay and web site. The information's which were obtained from different source were analyzed through table, graph and charts with some interpretation. Based on the result of the study, the main cause of water scarcity is limited number of reservoir and catchment, topography, high population growth, limited capital, and unskilled man power. Finally based on the result of the data the following recommendations were made; people should use family planning, and participate in water facility construction and rehabilitation. Whereas the government should create awareness for the communities regarding with water scarcity, cause consequence, proper utilization of water, must allocate more fund for water resource development, and should distribute water fairly.
\end{abstract}

Keywords: Water Scarcity, Sanitation Issues, Debre Tabor Tow

\section{Introduction}

\subsection{Background of the Study}

The blue colour shows the vast amount of water found on earth but this apparent abundant is a mirage. Indeed, only about $2 \%$ of the blue land scape visible is fresh water with the rest being salt water which is useless for normal human consumption [1]. To amplify the limitation of fresh water only about half of it is available for use by the everincreasing population of the world that is approaching 6 million.

Water is the most important resource and is vital for all life on the earth. The wellbeing and the development of our societies are dependent on the availability of water. This most precious resource is sometimes scared sometimes abundant and it always unevenly distributed, in space and time. For instance, Europe and Asia together have only $27 \%$ of world's fresh water through them accommodates about $70 \%$ of the world population [16]. Water availability is subject to seasonal variation, with rain between May and September (kermt), shorter rains in February or March (belg) and a dry season from October to February [22].

Globally 884 million people drink water from unimproved sources [21]. Disparities in the availability of safe water constitute one of the primary underlying determinants of global Health inequality $60 \%$ of child diarrhea death are attributable to unsafe water, sanitation and hygiene [6].

Water scarcity which can broadly be understood as lack of access to adequate quality of water for human and environmental use is increasingly being recognized in many countries as series and growing concerns. As a result, the term water scarcity is regard used by the media, government report, NGOs, international organization such as UN and 
DECD as well as in the academic literature, to high area where water resource are under pressure [9].

According to management option to enhance survival and growth 2006 report, one third of all nation of Africa suffered from clean water scarcity, but sub-Saharan Africa had the largest member of water stressed countries of any other place on the planet and of an estimated 800 million people who live in Africa 300 million live in a water stressed environment [2].

Ethiopia's economic slumps are largely self-inflicted resulting from the countries wars against Eritrea and Somalia. These land locked low income nation with $1,127,127$ square kilometres has a population estimated at $73,000,000$ people. Making it the biggest and the most populated country in the horn of Africa in comparison with its neighbourhood countries, Ethiopia is vulnerable to draught, while it sites at the centre of the Nile river which support the level hoods of $160,000,000$ people in the eastern and horn of Africa, very little cooperation on the regions many trans boundary water issues exists [28].

\subsection{Statement of the Problem}

According to Debre Tabor town water supply and sewerage services office, like other areas Debre Tabor town face water scarcity and it affect socio-economic condition of the societies as well as daily activities. Based on 2007 CSA report, Debre Tabor town has a total population of 87,627 and it categorized in to four Kebele's, namely Kebele01, Kebele 02, Kebele 03, Kebele 04 and have the population of 29,$339 ; 29,662 ; 10,609$, and 18,017 respectively.

From the total population 2,997 households are bill customer and it categorized in to Kebele 01; 930, Kebele 02; 903, Kebele 03; 645, Kebele 04; 519 households. As standard, households of Debre Tabor town get 60 litters water/ a day, but do to scared water, households unable to get this standard rather they get only 22.8 litters water /a day. From the total household only $59.2 \%$ were address water and the remaining $40.8 \%$ were still not address water [15]. The distribution of water is not enough and it leads to water scarcity in town.

\subsection{Objective}

\subsubsection{General Objective}

The general objective of this study was to investigate the impacts of water scarcity in Debre tabor town.

\subsubsection{Specific Objective}

The specific objectives were

To identify the factor that affects water scarcity in the study area.

To investigate the consequence of water scarcity on daily activates of human being in the study area.

To assess the situation of water scarcity in the study area.

\subsection{Research Question}

What are the factors which are responsible for water scarcity?

What is the consequence of water scarcity?

What look like the situation of water scarcity in Debre Tabor town?

\subsection{Significant of the Study}

This study will provide many importance's for different organization, policy maker, local communities, researchers and other peoples. It will provide information regarding with factors of water scarcity and its solution. For policy makers and government, it gives some regarding with factor of water scarcity and easily understands where water scarcities is occurred and give a solution for the problems. It may serve as sight for other researchers who want to conduct further studies regarding with factor of water scarcity and consequence on daily activities of human being It is also important for water and sanitation office to easily separate which area is affected by water scarcity and its factors.

\subsection{Scope of the Study}

The scope of this study in terms of area delimited to south Gondar zone especially in Debre tabor town. Because it is easy, accessible and short distance for the researchers and water scarcity the main problem of the town. It encompasses factors of water scarcity and its impacts on daily activities of Debre tabor town societies.

\section{Research Methods, Materials and Procedures}

\subsection{Location of Study Area}

Debre tabor town is the capital town of the south Gondar administrative zone which is located in North West central Ethiopia in Amhara region. It is found near Gunna Mountain which is the second highest point in Amhara region as well as in Ethiopia. Its absolute location lies between $11^{\circ}, 51^{\prime}, \mathrm{N}$ latitude and $38^{\circ} 01^{\prime}$, E longitude (Ethiopia Map Agency) with an elevation of 2,706 $\mathrm{M}$ above sea level, were as the relative location of Debre tabor town is bounded by, in the east abaregay Kebele, in the west Tsegure Kebele in the north Selameko Kebele. And the town for from $667 \mathrm{KM}$ north of Addis Ababa and $103 \mathrm{~km}$ South east of Gondar and $50 \mathrm{~km}$ east of lake Tana [14].

\subsection{Topography}

Topographically the town is characterized by undulating terrain with significant altitudinal variation. Its highest and lowest elevation of the town is 2,884, 2,440 meter above sea level respectively [14].

\subsection{Climate}

Debre tabor town is located in temperate climate type which receives seasonal rain fall and characterized by 
Dega climate zone with mean annual rain fall 1,553.7 $\mathrm{mm} /$ year. The maximum rainfall occurs in July or August. During summer rainfall is heavy and about $78 \%$ of the rainfall of Debre Tabor is during this season, and mean daily temperature is $18^{\circ}, \mathrm{c} /$ day (Amhara metrology station).

\subsection{Demographics}

Debre Tabor town has a total population of 87627 of whom 41957 are male 45670 are female. The majority of in habitats follows Ethiopian orthodox Christianity, with 96\%, while $3 \%$ of the population said they were Muslim and the remaining $1 \%$ was others [26].

\subsection{Economic Activities}

The main economic activity of Debre tabor town is dominated by commercial activities and manufacturing enterprise. The local urban to rural interrelation in the Debre tabor town and its surrounding has a great significant for the contribution of their business activities. In addition to this, industrial activities like Saba engineering and small cottage industries like grain mill, wood and metal work, bakeries etc. are actively engaging. The town has urban rural Kebele this means the rural Kebele live around the town these engage in mixed agricultural activities [13].

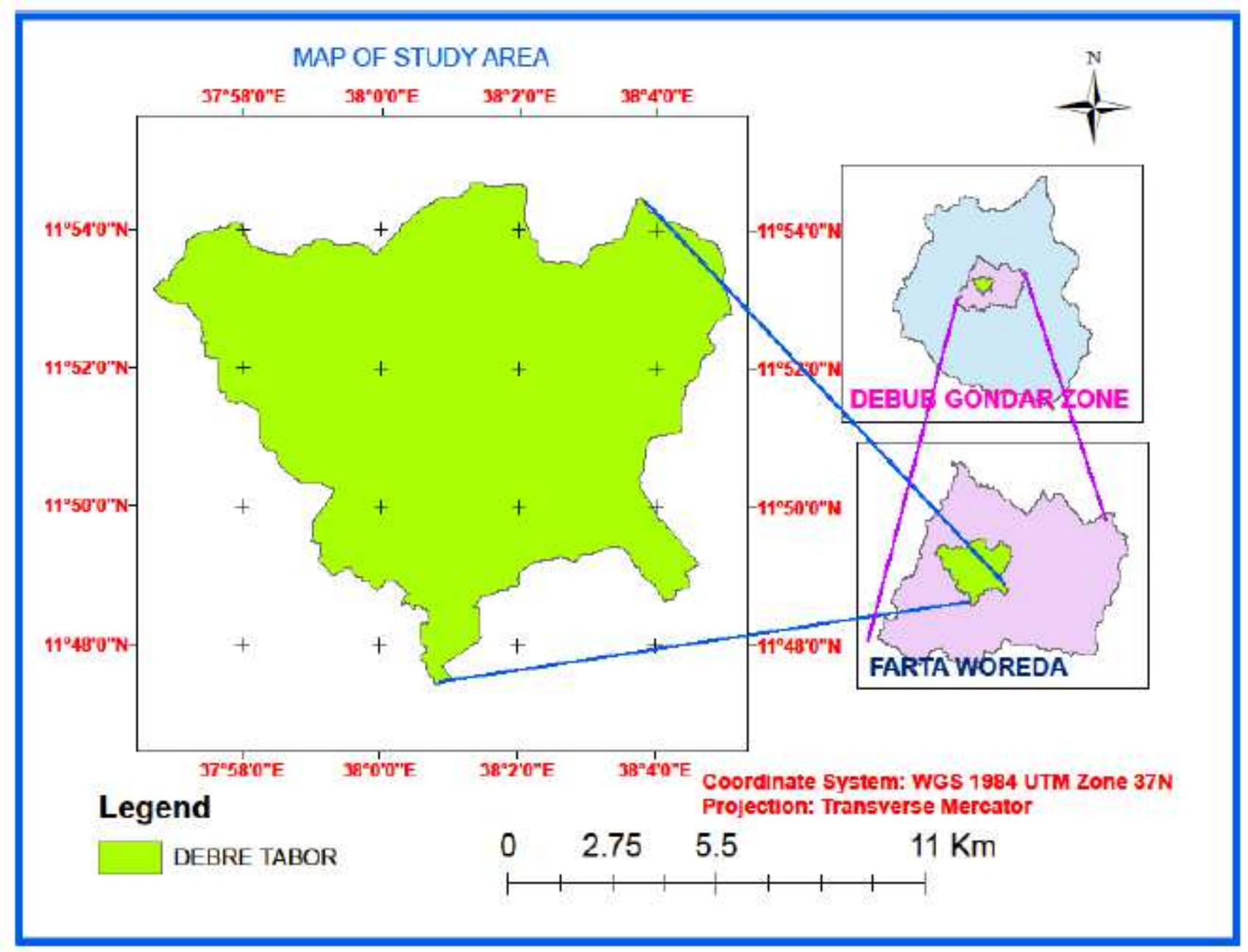

Figure 1. Map of study area.

\section{Study Design}

In order to undertake this study, the researcher was followed mixed approach research design (both qualitative and quantitative) data were collected through interview, questioners, observation. These data were used as supplementary information with qualitative data during analysis.

\section{Sample Size and Sample Technique}

In the study area there are about four kebele namely kebele01, kebele02, kebele03, kebele04. From those, kebele 01 and kebele 02 are selected as a sample by using simple random sampling technique. A researcher was need to assure that all the number of households who live in Debre tabor town were include in the list and they were randomly selected. The reason to use this simple random probable 
sampling technique is that to minimize the bias, and in order to give equal chance for the households who live in the town. The selected Keble's have 14,902 total households. Individually kebele 01 have 8,429 total households where as keble02 have 6,473 total households [8]. From the total

For total sample size

$\begin{array}{ll}\mathrm{n}=\frac{N}{1+N(\theta)^{2}}(\text { Yamane } 1967) & \text { where, } \mathrm{n}=\text { sample size } \\ \mathrm{n}=\frac{14,902}{1+14902(10 \%)} & \mathrm{N}=\text { total households } \\ \mathrm{n}=\frac{14,902}{1+14,902(0.1)^{2}} & \mathrm{e}=\text { level of precision } 10 \% \\ \mathrm{n}=\frac{14,902}{150} \quad \mathrm{n}=99.34 \approx 99 & \end{array}$

For each Keble

Kebele $01 \quad \mathrm{n}=\mathrm{ni}\left(\frac{N i}{N}\right)$ (Barreiro and albandoz, 2001)

$\mathrm{n}=99\left(\frac{8,429}{14,902}\right) \quad$ Where, $\mathrm{n}=$ sample size required from the $i^{\text {th }}$ Kebele

$\mathrm{n}=99(0.565) \quad \mathrm{ni}=$ total number of sample from selected Kebele

$\mathrm{n}=55.93 \approx 56 \quad \mathrm{Ni}=$ total number of household in $\mathrm{i}^{\text {th }}$ Kebele

$\mathrm{N}=$ total number of households in the selected area
Kebele 02

$$
\begin{aligned}
& \mathrm{n}=\mathrm{ni}\left(\frac{N i}{N}\right) \\
& \mathrm{n}=99\left(\frac{6,473}{14,902}\right) \\
& \mathrm{n}=99(0.4343) \quad \mathrm{n}=43.002 \approx 43
\end{aligned}
$$

Kebele $01,55.99 \approx 56$

\section{Data Source and Method of Data Collection}

\subsection{Data Source}

For this study a researcher was collected data from primary and secondary data source. Among the primary data source local communities and researchers were observed the study areas and gathered information from filed, were as secondary data were generated from books, articles, and website.

\subsection{Methods of Data Collection}

The researchers were used both primary and secondary data. The primary data were collected through filed observation, questionnaires, (both close ended and open ended), interview, and also the researchers were referred data's from published and unpublished secondary data source.

\subsection{Methods of Data Analysis}

To analyst the collected data from primary and secondary data source, researcher was used both qualitative and quantitative analysis techniques. The qualitative technique used to express the information in the forms of word and symbols like its impacts on health, and social relation, diseases, and drought and such like terms which is expressed in word, were as quantitative technique used to express in numerical values in terms of graph, chart, and percentage

\section{Data Analysis and Interpretation}

\subsection{Demographic Analysis}

\subsubsection{Sex Distribution of Respondents}

Sex structure is one of the demographic factors which affect social, economic and political aspect. As a result, this study identified the sex structure of respondent as follow.

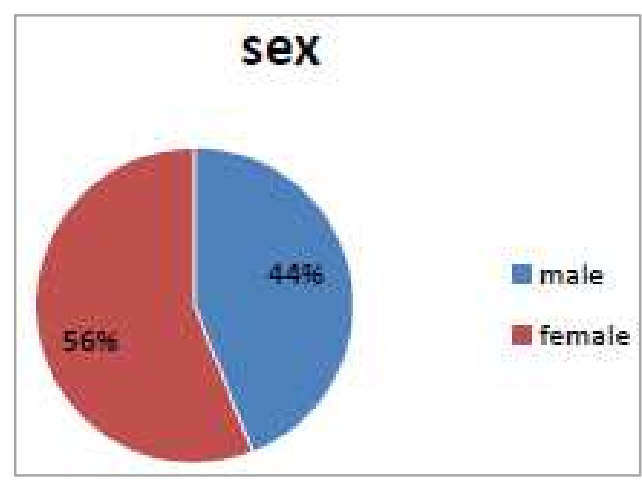

Source; field survey 2017

Figure 2. Sex Distribution of Respondents. 
Both male and female respondents were participated in this research. Majority of the respondents were females which account $56 \%$ and the remaining $44 \%$ were males.

\subsubsection{Age Distribution of Respondents}

Age is an important demographic character of respondent that influence the participation of respondent to solve water scarcity problem.

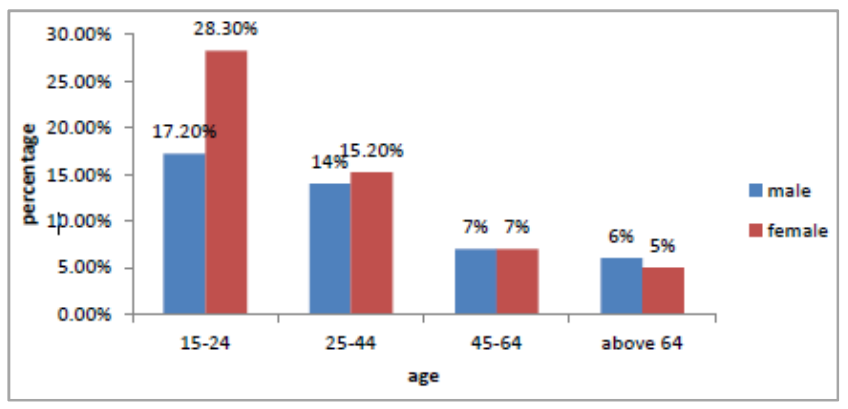

Source; field survey 2017

Figure 3. Age Distribution of Respondents.

As the above figure 4 shows that, majority of respondents were lay between age $15-24$ accounts about $45.5 \%$ both male and female. This age group is well known by its productivity and more powerful to perform any activities. The remaining $29.2 \%, 14 \%$, and $11 \%$ of respondents were ranging $25-44$, 45-64, and above 64 respectively. From thus age group the oldest above 64 years old have less contribute to water based activity, because as they were old less capacity to support water based activities by labor and money, instead they consume water.

\subsubsection{Marital Status of Respondents}

Marital status is another demographic factor of respondent which influence water consumption, participation on different activities. Most of the time a single individual has consumes less water when we compare than married because, during married there may be more than 2 families, and this condition may leads to high water demand.

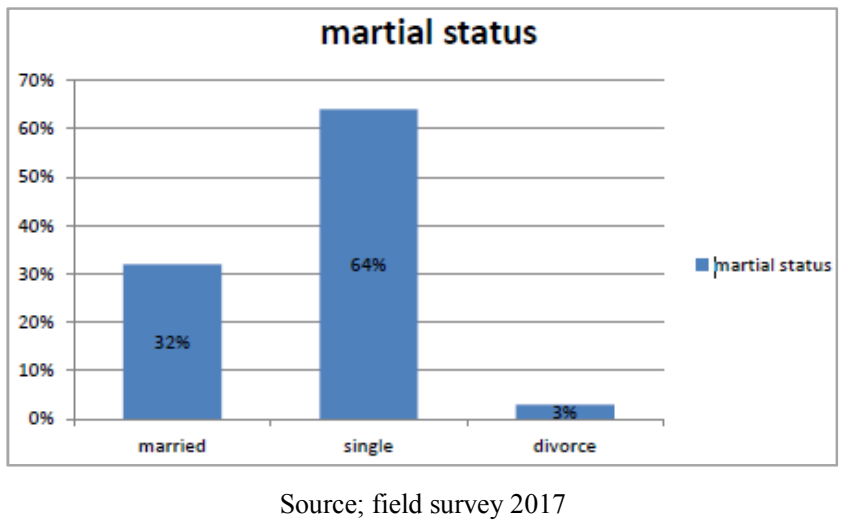

Figure 4. Marital Status of Respondents.

As the above figure shows that the majority of respondents $67 \%$ were single and the remaining $32 \%$ and $3 \%$ were married and divorce respectively.

\subsubsection{Occupation Distribution of Respondents}

Occupation is plays a major role to solve water scarcity of a certain region. Means each individual has a responsibility to participate to solve the problem according to its ability and experience. By nature, some occupation needs high amount of water like hotel. Such activities degrade water resource

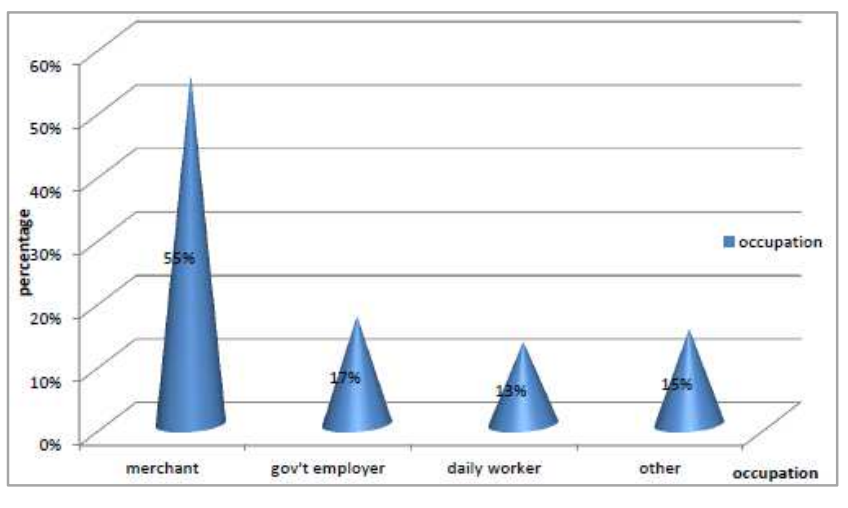

Source; field survey 2017

Figure 5. Occupation Distribution of Respondents.

As the above diagram result show that merchants were share the greatest portion about 55\% and the remaining government employer, other, and daily workers were share $17 \%, 15 \%$ and $13 \%$ respectively. Therefor as merchants they contribute a greater role for water based activities.

\subsubsection{Family Size}

Family size can affect water demand and consumption. That means family with greatest size need much amount of water and family with less family size need less water and less impact on water

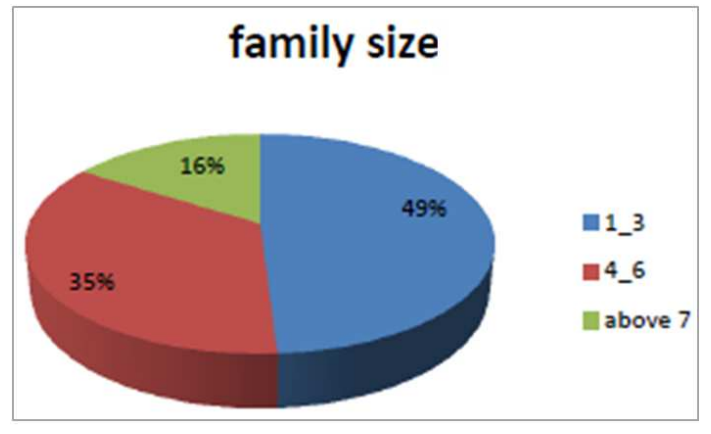

Source; field survey 2017

Figure 6. Family Size.

As we observe from the above figure the greatest portion of respondent family size were lay between 1-3 account about $49 \%$ were as from $4-6$ and above 7 share $35 \%$ and $16 \%$ respectively.

\subsubsection{Education Status of Respondents}

Education status is another factor which influences proper utilization of water as well as other natural resources. As a country has greater educated people, it plays a great role for its resource conservation, putting alternative to the existed problem as well as rehabilitation the degraded resource. On 
the other hand, country has high illiteracy rate their contribution for such activity is relatively less.

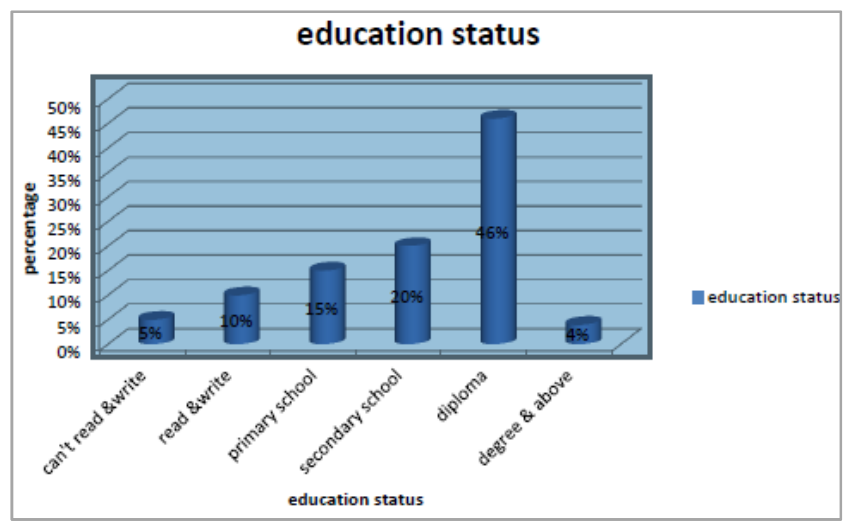

Source; field survey 2017

Figure 7. Education Status of Respondents.

\subsubsection{Monthly Income of Respondents}

Income of the societies has played a greater role to solve the problem of water scarcity. The greater income has the power to contribute many for the solution and the invers is true.

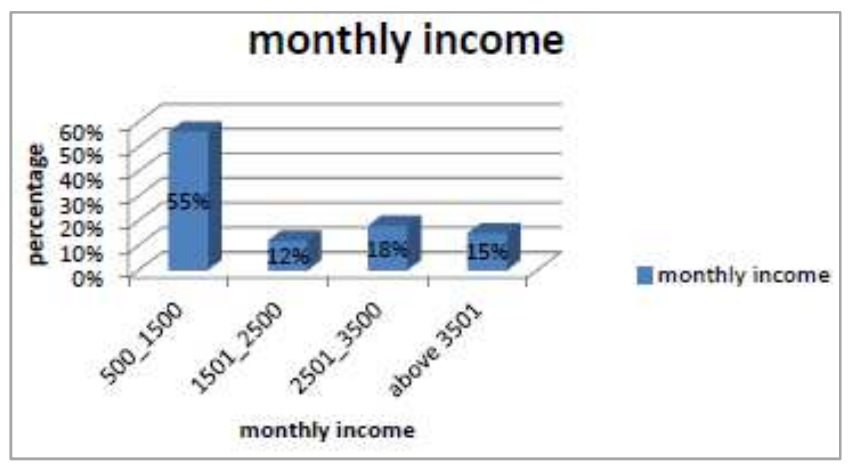

Source; field survey 2017

Figure 8. Monthly Income of Respondents.

As indicated in the above figure, most respondents have a capacity to support money to solve the problem of water scarcity. Its proportion is that $55 \%, 18 \%, 15 \%$ and $12 \%$ were $500-1500, \quad 1501-2500,2501-3500$ and above 3500 respectively.

\subsection{Water Scarcity in Debre Tabor Town}

Table 1. Water scarcity in debre tabor town.

\begin{tabular}{lll}
\hline $\begin{array}{l}\text { Is their water scarcityin debre } \\
\text { tabor town }\end{array}$ & frequency & Percentage \% \\
\hline Yes & 97 & 98 \\
no & 2 & 2 \\
Total & 99 & 100 \\
\hline
\end{tabular}

Source field survey 2017

According to the above table 1, much of sample respondents were respond, in Debre tabor town there is water scarcity. Out of 99 respondents about $98 \%$ were said that there is water scarcity and the remaining $2 \%$ were said that, there is no water scarcity in the area.

\subsection{Water Interruption per a Week}

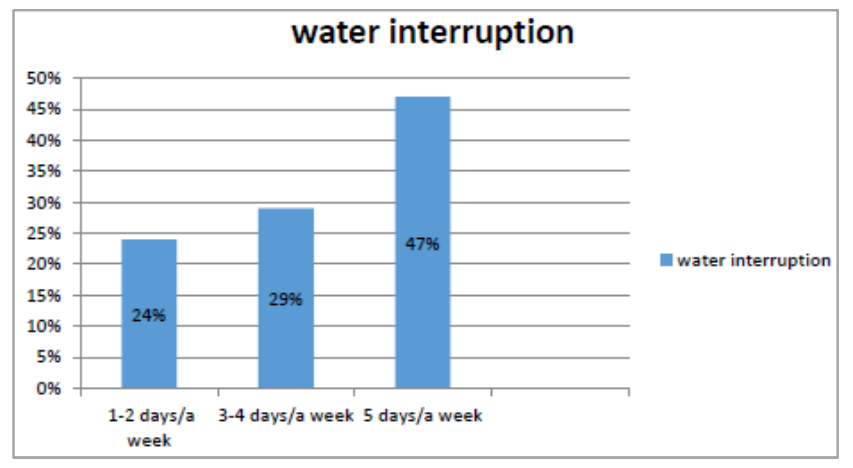

Source; field survey 2017

Figure 9. Water Interruption per a Week.

As indicated in the above figure 8, out of 99 respondents $47 \%$ respondents were asserted that water is interrupted 12 days per a week and $29 \%$, and $24 \%$ respondents were said that water is interrupted 3_4 and 5days per a week respectively.

\subsection{Water Distribution in Debre Tabor Town}

Most respondents were said that water distribution is classified in Keble. According to respondents answer, water is accessed for each Keble per a week as follow.

Table 2. Water distribution per a day.

\begin{tabular}{lll}
\hline For how many days do you get water per a week & frequency & Percentage (\%) \\
\hline day & 50 & 51 \\
d days & 26 & 26 \\
3 days and above & 23 & 23 \\
Total & 99 & 100 \\
\hline
\end{tabular}

Source; field survey 2017

As, indicated in the above table 1, out of 99 respondents $51 \%$ of respondents were said that, we get water 1day per a week. The remaining $26 \%$ and $23 \%$ respondents were said that 2 days and 3 days respectively.

\subsection{Amount of Water Distribution per a Day}

Utilization and demand of water is varying from individual to individuals as well as from household to households according to its family size, types of work and water supply 
for instance larger family size and hotel and restaurants utilize high amount of water than less family size and have little work. The result is portraying as follows.

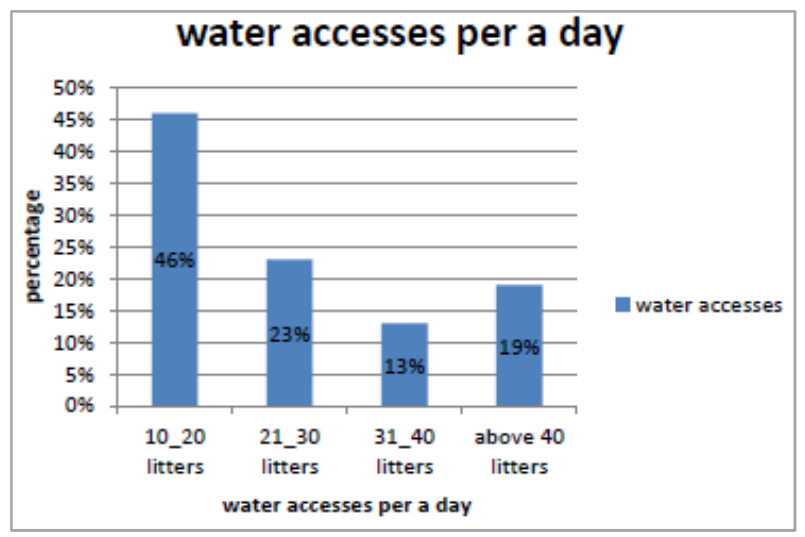

Figure 10. Amount of Water Distribution per a Day.

Household accessed water per litters per a day Source; own field survey 2017
As we observe from the above figure $46 \%$ as respondents were said that, they get 10-20 liters per a day. And the remaining $23 \%, 19 \%$ and $13 \%$ respondents were said they get 21-30, above 40 and 31-40 litters of water per a day.

\subsection{Natural, Human and Socioeconomic Cause of Water Scarcity in the Study Area}

As the above figure shows, out of 99 respondents 51\% were said that the main factor of water scarcity in the study area is limited number of water reservoirs and catchments. In Debre tabor town there are about four water reservoirs. They are the capacity to store up to $920 \mathrm{~cm}^{3}$ water. In addition to the main reservoirs, the town has four booster stations; they store up to $280 \mathrm{~cm}^{3}$ and also there are about 10 water catchments or source which provides water for the communities. These catchments are found around Ajibar, Shahena, Sebar deldey, Gafate (2), Mello, and kanat (4). The amount and capacity of water reservoirs and water catchments are not enough to preserve water needed by the population [15].

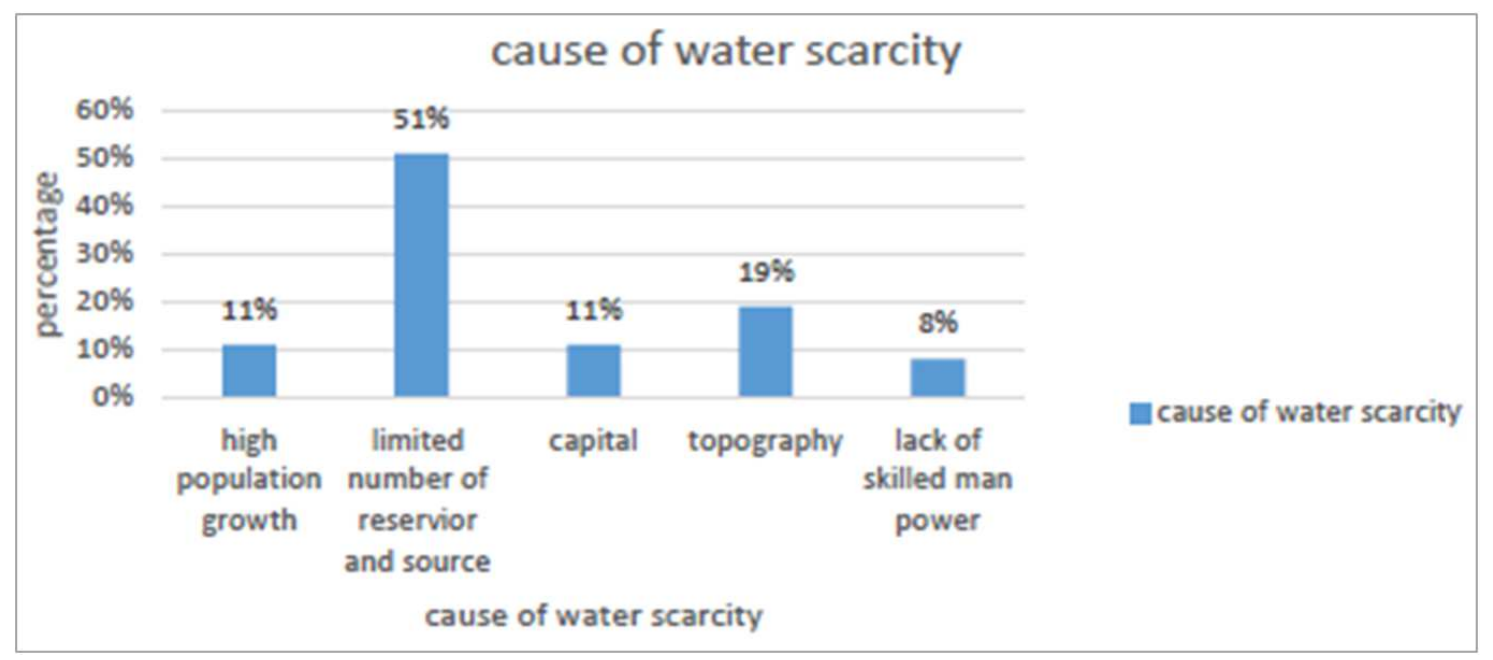

Source; own field survey (2017)

Figure 11. Cause of Water Scarcity in the Study Area.

Next to this the other factor is topography, which share $19 \%$. As topography of Debre tabor town characterized by undulating structure (up and down feature) this conditions hinder construction of reservoirs, pipe, and public tab.

The $3 \mathrm{rd}$ is that high population growth and capital which share equal percent about $11 \%$. When number of population increase this condition leads to intensify of water consumption, and also it would also bring industrialization (concrete industry) and urbanization which causes environmental problems which directly affect the quality of water supply through release of polluted water which removed from different sources.

The next which share equal percent with population growth is that capital, it also affects water availability through a town has little capital, though unable to construct enough construction of water reservoirs and catchments and necessary materials.
The final is that lack of skilled man power which shares $8 \%$. Because of limited skilled man power water scarcity exists, through unwise use of water, due to insufficient knowledge about proper utilization of water, and also water construction need skilled man power.

Within four kebele of Debre tabor town, mainly there are about 7 public tap which is functional know a day. People were buy water within 2.10 Ethiopian birr per $1 \mathrm{~cm}^{3}$ or 1000 litters. As we observe from the field and ask the people about the supply of water and its price, even if we have 7 public tap it is not enough to satisfy our need, because it interrupt and unable to accesses enough water as we want [15].

\subsection{The Negative Impact of Water Scarcity in the Area}

As we gathered information from respondents and concerned bodies water scarcity in Debre Tabor town can followed many negative impacts including on health daily 
activities and economic development of the peoples.

Many peoples who participate in different activities were suffered by water scarcity. For example, as we ask hotel workers, water scarcity is the main obstacle for their work, because without water any activities could not be performed. Due to this reason, unable to cook food, difficult to wash materials which are necessary for food predation, and also for washing themselves. These conditions may lead to economic declination and poverty.

Daily worker respond that they suffered water scarcity for washing, drinking and cooking purpose. Due to this reason they were affected by disease.

It is mentioned previously, when the people faced pip scarcity, they tried to use water from pond and spring. This condition leads them for poor health, because peoples are forced to use low quality from flowing streams and ponds which are contaminated. There are many water borne diseases that cause to people die, and this is also cause huge sanitation issues. Clinics, local restaurants, public place of convenience and many other places are forced to use very little water for cleaning. That compromises the health of stuff and people who use the facility.

\subsection{Source of Water When Pip Water Is Interrupted}

Table 3. Water source in the study area.

\begin{tabular}{lll}
\hline Source of water & Frequency & Percentage $\%$ \\
\hline Pond & 72 & 73 \\
Spring & 20 & 20 \\
Rain & 7 & 7 \\
Total & 99 & 100 \\
\hline
\end{tabular}

Source; field survey 2017

As indicated in the above table, out of 99 respondents $73 \%$ respondents were asserted that, 25 they get water from the pond during water is interrupted. The remaining $20 \%$ and $7 \%$ were said that, they get from river and rain respectively.

\subsection{Solution Should Be Taken by the Debre Tabor Town Water Supply and Sewerage Service Office}

Respondents were said that, the office has many duties which must be fulfill to the communities regarding with water supply.

Table 4. Solution that taken by the gov't.

\begin{tabular}{lll}
\hline Solution taken by the gov't & Frequency & Percentage $\%$ \\
\hline Construction of additional water reservoirs and catchment & 70 & 71 \\
Period of water distribution & 15 & 15 \\
Construction of additional water pipe & 14 & 14 \\
Total & 99 & 100 \\
\hline
\end{tabular}

Source field survey 2017

As illustrated in the above table, in order to solve water scarcity problems, the government was taken different activities. Out of 99 respondents, $71 \%$ were said that construction of additional water reservoirs and catchments, and the remaining $15 \%$ and $14 \%$ of respondents were said that classify period of water distribution and construction of additional water pipe respectively.

\section{Conclusion and Recommendation}

\subsection{Conclusion}

Even though much of the earth surface is covered by water, clean water scarcity is the current major problem in the study area as well as in the world. Major factors which were the cause for water scarcity in the study area are, limited number of water reservoir and catchments, high population growth, limited capital to construct different infrastructure for water, less skilled man power and up and down structure of the earth surface. Due to the above factor the supply of water in the area does not satisfy the need of societies for different activities. As the study indicate the majority of population obtained water from ponds and springs when water is interrupted. Due to this reason the societies are affected by water born disease and poverty. This problem can affect economic development as well as daily activity of human beings.

\subsection{Recommendation}

Standing from the result of this research, the researchers was suggesting the following recommendation for concerned bodies like local communities and Debre tabor town water supply and sewerage service.

For local communities

1) People should utilize water properly.

2) People should Support construction of water infrastructure in terms of money, labor, material and knowledge.

3) Population should apply water harvesting during rainy season.

4) Peoples should properly treat wastes from industries as well as domestic uses

For Debre tabor town water supply and sewerage service office

1) The office should creating awareness for the communities regarding with water scarcity, cause, consequence and proper utilization of water

2) The office must allocate more funds for water resource development and for additional construction of water reservoirs, catchments and public taps.

3) The office should be distributing water to the societies fairly.

4) The office should have schedule to meet with the local 
communities, in order to collect information about the situation of the problems.

Generally, in order to solve the problem, the peoples must work together with the government.

\section{References}

[1] Alcamo.., P. Doll, (2003), "Global estimates of water withdrawals and availability under current and future' business -as-usual' conditions. Hydrological Science Journal 48 (3): 339-348.

[2] Archive conference of water scarcity in Africa, issues and challenges Retrieved 11 November 2016.

[3] Barrieiro, p. 1 \& Albandoz, J. P. (2001). population and sample and sampling techniques. Management mathematics foreuropeanschools, Retrieved 5 March, 2016, from http://optimerung.Mathematik.

[4] Boschipint C velebitL. shibuya K. (2008), estimating children mortality due to hiarrhela in developing countries Bulletin of the world health organization.

[5] Census, (2007), Tables, Tigray Region. Archived November 14,2010 , at the way back machine.
[6] Chriswhite (2012), understand water scarcity: definition and measurement, Australia national university Australia.

[7] Debre Tabor town administrative office (2007).

[8] Debre Tabor Town report, (2013).

[9] Debre Tabor town water supply and sewerage service office 2009 , report.

[10] Dr. P Joyamic Readdy (2013), text of hydrology: 3rd edition.

[11] Jamp (Wtto/UN/CEF Join maintaining program) Progress on sanitation and drinking water, 2010 up date, GenevaNewyork: world health organization/United nation children found: 2010 .

[12] Kloose. H, Zein ZA, (1992) The ecology of health and disease in Ethiopia.

[13] South Gondar zone population and affair office (2009), report.

[14] Valerie Naduzanie (2011): water scarcity in Ethiopia risk and vulnerability assessment.

[15] Yamane Jaro (1967), statistics an introductory analysis and New work, Harper and row. 